Tuberculosis

\section{An unusual presentation of calvarial tuberculosis}

\section{S K G Samson, V Kulkarni, A G Chacko}

\section{Authors' affiliations}

S K G Samson, V Kulkarni, A G Chacko,

Department of Neurological Sciences, Christian Medical College and Hospital, Vellore, Tamil Nadu 632004, India

Correspondence to: Dr Chacko; agchacko@cmcvellore.ac.in

Submitted 2 August 2001

Accepted 21 August 2001

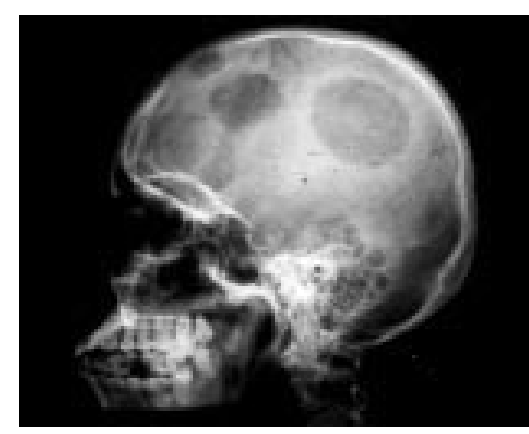

Figure 1 Plain radiograph (lateral view) of the skull showing well circumscribed lytic lesions in the right frontal, right parietal, and left frontal regions. table. There was neither subgaleal nor extradural abnormal enhancing soft tissue near the lesions. There were no parenchymal lesions in the brain.

\section{QUESTIONS}

(1) What is the differential diagnosis and what other investigations are indicated? (2) What are the different forms of calvarial tuberculosis and what is the common presentation?

(3) What is the management of this condition and indication for surgery?

Postgrad Med J 2002;78: 184-184 